\title{
Earthquake hazard in Indian region
}

\author{
K N KHATTRI \\ Wadia Institute of Himalayan Geology, Dehradun 248001, India
}

\begin{abstract}
The causes of earthquakes and their incidence in the Indian region have been briefly reviewed. The basic elements of probabilistic seismic hazard analysis, which is a basis for making pragmatic decisions for strategies for hazard reduction and mitigation, are discussed. A probabilistic seismic hazard map of the Indian region, which delineates the seismic hazard in various regions in terms of peak ground accelerations expected to be exceeded with a probability of $10 \%$ in any 50 -year period, is presented. The need and scope for further research are outlined.
\end{abstract}

Keywords. Earthquakes; seismic hazard analysis; seismic source zones; disaster mitigation strategies; faults; seismicity data; magnitude.

\section{Introduction}

India has suffered four great earthquakes of magnitudes 8.5 and greater, in the past hundred years, inflicting heavy casualties and economic damage. Yet, human memory being short, it is generally not recognized that we continue to live under the long shadow of such future calamities. One of the ways to mitigate the destructive impact of earthquakes is to conduct a seismic hazard analysis and take remedial measures.

Seismic hazard analysis consists of estimating various effects such as ground failure by faulting or soil liquefaction, ground shaking, tsunami generation etc. that might be caused by future earthquakes in a region.

The occurrence of earthquakes, for all practical purposes, is presently unpredictable with precision. Also, the effects of earthquakes such as ground shaking, ground failure etc. are quite variable. Thus, their analyses and parameterization have to be suitably done in a probabilistic framework. Strong ground shaking is the most widespread agent of earthquake hazard. Seismic hazard due to shaking is, therefore, the most frequently mapped, which provides probability estimates at given sites of the ground motion (displacement, velocity or acceleration) that will not be exceeded in the wake of future earthquakes in a given interval of time. Such parameterization can therefore form a rational basis for balanced decision-making in planning the whole gamut of hazard mitigation strategies.

Seismic hazards in a region may then also be translated into seismic risk by using a loss function that will include life as well as economic activity. In this paper, we review the construction of a probabilistic seismic hazard map of the country. 


\section{Causes of earthquakes}

The immediate cause of a great majority of earthquakes is faulting. Stresses in the crust are steadily generated by the relative motion of plates, which are components of the fractured outermost shell of the earth. Cyclic release of these stresses owing to the finite strength of rocks and their reaccumulation provides a sustained environment for earthquake recurrence along plate margins, such as the Himalaya, as well as in the plate interior, such as the Indian shield, although the operative mechanisms there are not so well defined.

Source zones

For seismic hazard analysis in a region, one begins with identifying the possible sources of future earthquakes. Past seismicity together with the model of regional tectonics is the basis for identifying seismic source zones. Since faults are the principal cause of earthquakes, one needs to identify such faults that are potential sources of future earthquakes. These faults have to be modelled in three dimensions. Furthermore, the random occurrence of smaller and moderate-sized earthquakes called background seismicity must also be considered in a source zone defined around active faults.

In many regions, earthquakes are caused by blind faults which have no direct expression on the surface and are difficult to model. In such places, one defines a source zone in which earthquakes can occur. The outlines of source zones are governed by aerial distribution of past earthquakes and geological considerations governing active tectonics. Figure 1 shows the seismicity of the Indian region and the identified seismic source zones (Khattri et al 1984).

\section{Recurrence relation}

The temporal distribution of earthquakes in a source zone is modelled by the recurrence relation,

$$
\log _{10} N_{c}(M)=A-B M
$$

where $N_{c}(M)$ is the number of earthquakes of magnitude equal to or greater than $M$, that occur during a unit time interval (say one year) in a unit area (say $100 \mathrm{~km}^{2}$ ), $A$ and $B$ being parameters specific to a particular source zone. This is the cumulative magnitude recurrence relation. The return period of an earthquake with magnitude $M$ or greater is given by $1 / N(M)$ years.

Recurrence parameters are usually estimated by using a regression analysis of historical seismicity data. These are now being supplemented by paleoseismicity data, wherever possible, as they provide important constraints on the frequencies of large earthquakes that have long return periods. Historical seismicity data for such large and great earthquakes are often deficient owing to short time windows usually available, but a moving time-cum-magnitude window may be used to compensate for incompleteness of catalogs. 


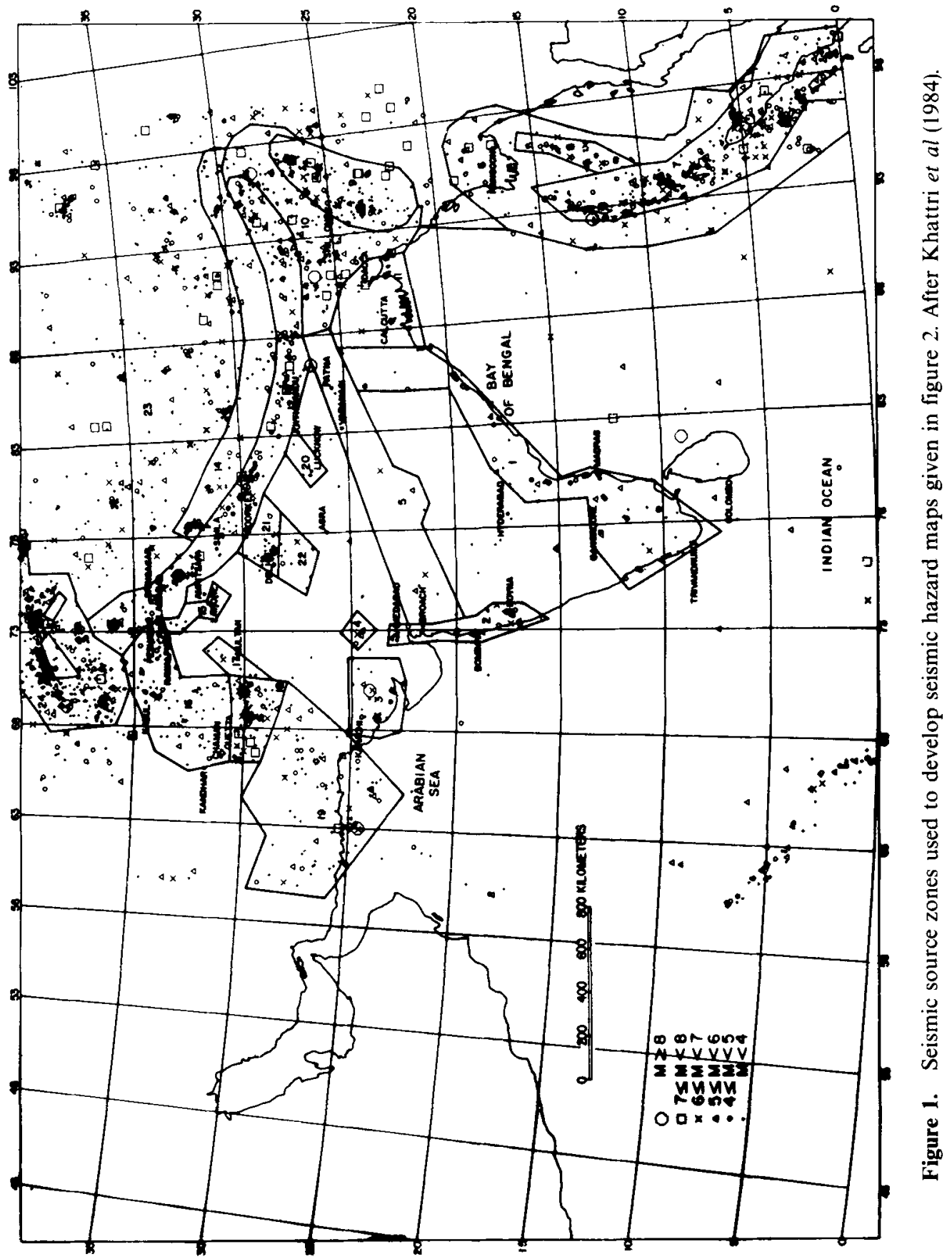




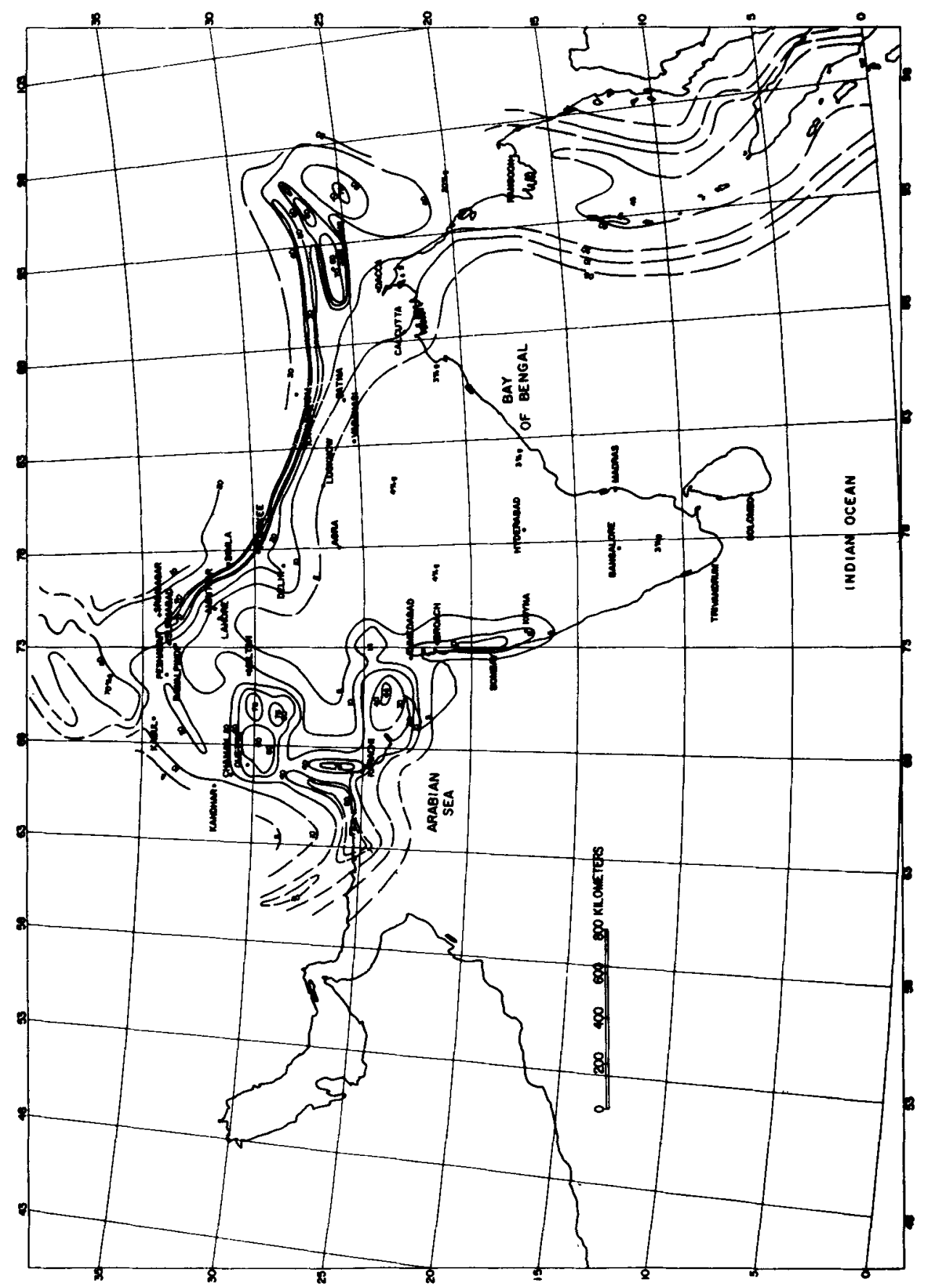

$?$
0
0
0

$\stackrel{2}{*}$

宛

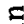

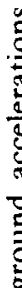

ב

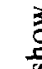

苛

$\stackrel{0}{0}$

.

을

总

巳

च

奇这

争娄

D

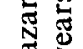

중

응 요

E

'ั

․ㅛㅁ

i 


\section{Maximum magnitude earthquake}

One also estimates the maximum possible earthquake magnitude for each zone. This is done on the basis of the model of tectonic processes responsible for seismicity in the region as well as the record of past earthquakes.

\section{Attenuation laws}

Since strong ground shaking is the immediate cause of widespread destruction during an earthquake, probabilistic hazard maps often map some single parameter to represent it. Usually, it is the peak ground acceleration or the peak ground velocity. The occurrence of an earthquake is thus translated into one of a peak ground motion parameter (usually acceleration) at various sites using empirical attenuation relationships of the type,

$$
\log Y=a+b+d \log p[R+c(M)]+e R+G,
$$

where $Y$ is a given ground motion parameter, $M$ the earthquake magnitude, $R$ the source-to-site distance, $c(M)$ is a term that reflects the behaviour of the relationship at small distances and large magnitudes, and $G$ is a zero mean Gaussian random error term describing the variability in ground motion. The relation is established using regression analysis. It may be noted that prediction of $Y$ is dependent on local and regional site geology.

\section{Modelling of extreme accelerations}

Temporal sequence of earthquakes in a source region is usually modelled as a Poisson process. This model assumes the density distribution to be homogeneous in time, i.e. events are independent in time and are identically distributed. The distribution of earthquakes in space may be suitably modelled to reflect the nature of tectonics in the source region.

The extreme probability $F_{\max , t}(\mathbf{a})$ of peak ground acceleration is mapped in probabilistic seismic hazard maps. This is the probability that at a particular site an observed peak ground acceleration a will not be exceeded in a time window of $t$ years. If earthquakes are represented by a Poisson distribution with a mean occurrence rate $\lambda$, the corresponding peak ground accelerations at a site will also follow the same distribution.

To introduce the time element, we let $\lambda=p t$, where $p$ is the mean rate of occurrence of earthquakes per year and $t$ is the time interval of interest. The extreme probability can then be written as (Khattri et al 1983),

$$
F_{\max . t}(\mathbf{a})=\exp \left\{-t / R P_{Y}(\mathbf{a})\right\}
$$

where $R P_{Y}$ is the return period in years of peak ground acceleration equal to or greater than $\mathbf{a}$.

The return period of maximum ground acceleration in an exposure period of 50 years, with a $90 \%$ probability of not being exceeded, is approximately 475 years.

A probabilistic earthquake hazard map of India and the surrounding region prepared in this way is shown in figure 2. The mapped peak ground accelerations 
are in the neighbourhood of $70 \% \mathrm{~g}$ in the Himalaya which is the most vulnerable region of the country. Peak ground accelerations in Peninsular India by comparison are smaller, generally of the order of less than $10 \% \mathrm{~g}$. Hazard is considered to be negligible for peak ground acceleration (pga) $<0.05 \mathrm{~g}$; low for $0.05 \mathrm{~g}<\mathrm{pga}<0.1 \mathrm{~g}$; moderate for $0.1 g<$ pga $<0.2 g$; high for $0.2 g<$ pga $<0.4 \mathrm{~g}$; and severe for $0.4 \mathrm{~g}<$ pga. We emphasize here that the map is for an exposure period of only 50 years. As the exposure period is increased the expected peak ground acceleration values will also increase. The return period of damaging earthquakes in the Himalaya is relatively small, of the order of a few years. In the peninsula, seismicity is feebler and damaging earthquakes are known to occur at considerably longer intervals. Their sizes are also relatively smaller. However, since the return periods of these earthquakes are long and unknown, there is considerable uncertainty about the accumulated strain levels in different parts of the peninsula, even as long periods of quiescence create an illusion that the region is safe from earthquakes. Meanwhile, centres of dense anthropogenic activities have become quite concentrated all over India, with hardly any preparation to face unsuspected earthquake hazards. This has been sadly brought home to us by the recent Uttarkashi and Killari (Maharashtra) earthquakes.

It is generally not appreciated that this country as a whole is not properly prepared to deal with earthquake hazards in a scientific and planned manner. Barely any systematic steps have been taken to prepare quantitative hazard maps on regional or local scales, not even for regions selected for the establishment of megacities or construction of large structures such as dams, nor has the use of concepts such as Baeysian estimates, compound probability distributions, information theoretic analysis, synthesis of earthquake-strong ground motion time histories, fractal descriptions, and newer data for seismic hazard maps been made to estimate hazards in the absence of adequate high quality data. Indeed, there is urgent need for a map depicting anticipated economic losses due to earthquakes and a plan for constructive social response in the wake of a damaging earthquake. Recent massive disasters caused by the moderate Uttarkashi and Killari earthquakes have underlined the grave necessity of designing and implementing a comprehensive earthquake disaster mitigation plan backed by hard research and sophisticated conceptual approaches.

\section{References}

Khattri K N, Rogers A M, Perkins D M 1983 Estimates of seismic hazard in northwestern India and neighbourhood. Bull. Inst. Seismol. Earthquake Technol. 20: 1-22

Khattri K N, Rogers A M, Perkins D M, Algermissen S T 1984 A seismic hazard map of India and adjacent areas. Tectonophysics 108: 93-134 